\title{
Decentralized Fiscal Federalism Revisited: Optimal Income Taxation and Public Goods under Horizontal Leadership*
}

\author{
Thomas Aronsson and Lars Persson \\ Department of Economics, Umeå University, \\ SE - 90187 Umeå, Sweden
}

February 2012

\begin{abstract}
This paper concerns optimal taxation and public goods in an economic federation with decentralized leadership, where one lower level government is first mover also in the horizontal dimension. Under plausible assumptions, horizontal leadership reinforces the incentives created by decentralized leadership.

Keywords: Optimal taxation, redistribution, public goods, fiscal federalism, decentralized leadership, horizontal leadership

JEL classification: D31, D60, D82, H21
\end{abstract}

${ }^{*}$ The authors would like to thank Magnus Wikström for helpful comments and suggestions. Research grants from the Bank of Sweden Tercentenary Foundation, the Swedish Council for Working Life and Social Research, and the National Tax Board are also gratefully acknowledged. 


\section{Introduction}

During the latest decade, a literature on public policy under decentralized fiscal federalism has gradually evolved, where lower levels of government act as strategic leaders vis-a-vis a higher level of government. A major reason for analyzing public policy in such a framework is that the European Union (EU) has become an increasingly important actor in European public policy by redistributing among its member states as well as providing certain public goods. It is often argued that the EU exemplifies an economic federation with decentralized leadership, since the member states may already have pre-committed to their own tax and expenditure policies, and the member states have a significant influence over union policy through the Council of Ministers. As a consequence, the federal (supranational) level typically carries out redistribution and other policies after observing the policies decided upon by the member states. Earlier research on public policy in economic federations with decentralized leadership includes a variety of themes such as local/regional provision of public goods (e.g., Caplan et al., 2000; Köthenbürger, 2007; Caplan and Silva, 2010), optimal redistributive taxation (Aronsson, 2010), tax competition (Köthenbürger, 2004) and environmental policy (e.g., Silva and Caplan, 1997; Caplan and Silva, 1999; Aronsson et al., 2006).

The present paper revisits the area of optimal nonlinear taxation and public good provision under decentralized fiscal federalism and is based on a modified version of the two-country and two-type model used by Aronsson (2010). The extension here is that we consider decentralized and horizontal leadership simultaneously. This is important because the ability of commitment may differ among the member states of an economic federation for a variety or reasons such as differences in size, resources, and the length of membership. A country with the ability to commit horizontally may also have incentives to exercise this commitment power; one reason emphasized below is that horizontal leadership provides an additional channel through which a national government can derive benefits from federal redistribution. As such, even if the member states as a group behave as strategic leaders vis-a-vis the federal level, they are not necessarily Nash-competitors to one another, which is the assumption made in earlier literature on decentralized fiscal federalism. Our concern here will be to analyze this mixture of incentives faced by the horizontal leader. The model and main results are presented in Section 2 and 3, respectively.

\section{The Model}

Consider an economic federation comprising a given number of lower-level jurisdictions, referred to as countries, and a federal government. As the number countries is, by itself, of no concern, it will be normalized to two. Each country has its own revenue collection and public good provision, whereas the role of the federal government is to redistribute lump-sum between the countries in terms of public funds. 


\subsection{Private Sector}

The utility function facing ability-type $i$ in country $j$ is given by

$$
u_{j}^{i}=u\left(c_{j}^{i}, z_{j}^{i}, g_{j}\right)=\tilde{u}\left(c_{j}^{i}, z_{j}^{i}\right)+v\left(g_{j}\right)
$$

where $c$ is the consumption of a private good, $z$ is leisure defined as a time endowment less the hours of work, $h$, and $g$ is the consumption of a (national) public good. We assume that $\tilde{u}(\cdot)$ and $v(\cdot)$ are increasing in their respective arguments and strictly concave, and that private consumption and leisure are complementary in the sense $\partial^{2} u_{j}^{i} / \partial c_{j}^{i} \partial z_{j}^{i} \geq 0$.

The budget constraint of the consumer is written as

$$
w_{j}^{i} h_{j}^{i}-T_{j}\left(w_{j}^{i} h_{j}^{i}\right)-c_{j}^{i}=0
$$

where $w$ is the gross wage rate, while the function $T_{j}(\cdot)$ is the income tax decided upon by the national government in country $j$. The price of the private consumption good has been normalized to one. Each consumer obeys the first order condition

$$
\frac{\partial u_{j}^{i}}{\partial c_{j}^{i}} w_{j}^{i}\left[1-T_{j}^{\prime}\left(w_{j}^{i} h_{j}^{i}\right)\right]-\frac{\partial u_{j}^{i}}{\partial z_{j}^{i}}=0
$$

where $T_{j}^{\prime}\left(w_{j}^{i} h_{j}^{i}\right)=\partial T_{j}\left(w_{j}^{i} h_{j}^{i}\right) / \partial\left(w_{j}^{i} h_{j}^{i}\right)$ is the marginal income tax rate. Note that the assumption of additive separability in the utility function means that $h_{j}^{i}$ does not depend directly on $g_{j}$.

Output is produced by a linear technology such that the gross wage rates are fixed.

\subsection{Public Sector Objectives and Budget Constraints}

Let $j=f$ denote the horizontal follower and $j=l$ the horizontal leader. Since our main concern is to characterize the optimal redistributive tax policy and public good provision from the point of view of the horizontal leader, we abstract from internal redistribution in the follower country and assume, instead, that the follower country is populated by only one ability-type, while the country acting horizontal leader is populated by two ability-types. This will simplify the calculations considerably and is also motivated by the fact that optimal taxation and public provision under decentralized leadership has already been addressed in a two-type framework by Aronsson (2010) under the assumption that the countries are Nash-competitors to one another. ${ }^{1}$

The objective at each level of government is represented by a social welfare function. For the horizontal follower, the social welfare function is given as $U_{f}=u\left(c_{f}, z_{f}, g_{f}\right)$, while the social welfare function facing

\footnotetext{
${ }^{1}$ Since the horizontal follower behaves as a Nash-competitor, it follows that the policy rules for optimal taxation and provision of national public goods obeyed by a horizontal follower country with two ability-types are analogous to the corresponding policy rules derived under Nash-competition by Aronsson (2010).
} 
the horizontal leader becomes $U_{l}=\sum_{i} \alpha_{l}^{i} u\left(c_{l}^{i}, z_{l}^{i}, g_{l}\right)$ where $\alpha_{l}^{i}$ is the welfare weight attached to ability-type $i$ and $\sum_{i} \alpha_{l}^{i}=1$. The objective of the federal government is assumed to be a weighted sum of the national social welfare functions, i.e. $U=\beta_{f} U_{f}+\beta_{l} U_{l}$, where $\beta_{f}+\beta_{l}=1$. Denoting by $s_{f}$ and $s_{l}$ the transfer payment to the horizontal follower and horizontal leader, respectively, from the federal government, the budget constraints faced by the federal government and the two national governments can be written as

$$
\begin{aligned}
s_{f}+s_{l} & =0 \\
T_{f}\left(w_{j} h_{f}\right)+s_{f}-g_{f} & =0 \\
\sum_{i} T_{l}\left(w_{l}^{i} h_{l}^{i}\right)+s_{l}-g_{l} & =0 .
\end{aligned}
$$

\section{Public Policy}

The order of decision making is as follows: (i) the horizontal leader decides upon its own tax and expenditure policy while recognizing how the horizontal follower, the federal government, and the domestic private sector will respond to policy; (ii) the horizontal follower decides upon its tax and expenditure policy treating the policy by the horizontal leader as exogenous, while recognizing how the federal government and domestic private sector respond to policy; (iii) the federal government decides upon redistribution while treating the national policy variables as exogenous; and (iv) the private sector decides upon labor supply and consumption treating all policy variables as exogenous. Since we have already examined the private decision-problems, we continue by solving the policy problem sequentially starting by characterizing the federal government. All agents (private as well as public) are assumed to fulfill their respective second order conditions for maximum.

\subsection{Federal Government}

The federal government redistributes lump-sum in terms of public funds and chooses transfer payments, $s_{f}$ and $s_{l}$, to maximize $U=\beta_{f} U_{f}+\beta_{l} U_{l}$ subject to equations (4a)-(4c), while treating the functional forms and parameters of the national income tax functions (i.e. $T_{j}(\cdot)$ for $\left.j=f, l\right)$ as exogenous. Since individual utility is additively separable in the public good, the first order condition for this problem can be written as

$$
\beta_{l} \sum_{i} \alpha_{l}^{i} \frac{\partial u_{l}^{i}}{\partial g_{l}}=\beta_{f} \frac{\partial u_{f}}{\partial g_{f}}=0 .
$$

By noticing that $s_{l}=-s_{f}$ from the federal government's budget constraint, and using $T_{j}\left(w_{j}^{i} h_{j}^{i}\right)=w_{j}^{i} h_{j}^{i}-c_{j}^{i}$ from the private budget constraints, equation (5) implicitly defines a reaction function

$$
s_{l}=s_{l}\left(\overline{h_{l}^{1}}, \bar{c}_{l}^{1},-\overline{h_{l}^{2}}, c_{l}^{2}, \stackrel{+}{h_{f}}, \overline{c_{f}}\right)
$$


where the sign above each argument indicates the qualitative comparative statics effect. Equation (6) illustrates how the national governments may influence the federal transfer payments through tax policy. ${ }^{2}$ Since the federal government redistributes ex-post, each national government may increase the transfer payment it receives from the federal government by reducing its own public revenue (through a smaller $h$ and/or larger $c$ ).

\subsection{Horizontal Follower}

The direct decision-problem facing the horizontal follower is to choose $h_{f}, c_{f}$ and $g_{f}$ to maximize $U_{f}=$ $\tilde{u}\left(c_{f}, z_{f}\right)+v\left(g_{f}\right)$ subject to the budget constraint and reaction function for the federal transfer payment given by equation (4b) and (6), respectively, while treating $h_{l}^{1}, c_{l}^{1}, h_{l}^{2}$ and $c_{l}^{2}$ as exogenous. By combining the first order conditions of this problem with equation (3), it follows that the government in country $f$ implements the desired combination of work hours, private consumption and public consumption through a zero marginal income tax rate, i.e. $T_{f}^{\prime}\left(w_{f} h_{f}\right)=0$, accompanied by lump-sum redistribution and the the following policy rule for the public good: $M R S_{g, c}^{f}=1-M R S_{g, c}^{f}\left[\partial s_{l} / \partial c_{f}\right]>1$, where $M R S_{g, c}^{f}=\left[\partial u_{f} / \partial g_{f}\right] /\left[\partial u_{f} / \partial c_{f}\right]$. The intuition behind these results is discussed (in the context of a slightly more general model) in Aronsson (2010).

By using the first order conditions from the horizontal follower problem, we can derive reaction functions through which the horizontal leader may directly affect the policies decided upon by the horizontal follower. The properties of these reaction functions are driven by two distinct incentive effects; (i) changes in $h_{l}^{1}$, $c_{l}^{1}, h_{l}^{2}$ and $c_{l}^{2}$ directly affect $s_{l}$ and, therefore, the incentive faced by the follower to raise domestic public revenue, and (ii) changes in $h_{l}^{1}, c_{l}^{1}, h_{l}^{2}$ and $c_{l}^{2}$ affect the incentives of the horizontal follower to exercise vertical commitment power by altering the magnitudes of the derivatives $\partial s_{l} / \partial h_{f}$ and $\partial s_{l} / \partial c_{f}$. As such, incentive effect (ii) depends on the second order derivatives of the function $s_{l}(\cdot)$ which, in turn, depend on the third order derivative of the function $v(\cdot)$, i.e. incentive effect (ii) vanishes if $\partial^{3} v\left(g_{j}\right) /\left(\partial g_{j}\right)^{3}=0$ (in which case the utility of the public good is given by a quadratic function). If incentive effect (i) dominates, which appears to us as plausible, the reaction functions have the following properties:

$$
\begin{aligned}
& h_{f}=h_{f}\left(\overline{h_{l}^{1}}, \overline{c_{l}^{1}}, \overline{h_{l}^{2}}, \bar{c}_{l}^{2}\right) \\
& c_{f}=c_{f}\left(\stackrel{+}{h_{l}^{1}}, \overline{c_{l}^{1}}, \stackrel{+}{h_{l}^{2}}, \overline{c_{l}^{2}}\right) \text {. }
\end{aligned}
$$

The intuition behind equations (7) is as follows: if the horizontal leader reduces its public revenue in order to increase $s_{l}$ (through a smaller $h_{l}^{i}$ or larger $c_{l}^{i}$ ), the horizontal follower reacts to this "exogenous" decrease in transfer income by increasing its own domestic public revenue (which shows up as a larger $h_{f}$ and/or smaller $c_{f}$ ). On the other hand, if incentive effect (ii) dominates, the comparative statics properties of the

\footnotetext{
${ }^{2}$ Each national government has access to a general income tax. As such, it is able to perfectly control the choices of work hours and consumption by domestic residents.
} 
reaction functions for $h_{f}$ and $c_{f}$ become ambiguous (irrespective of the sign of the underlying third order derivative of $v(\cdot))$.

\subsection{Horizontal Leader}

The main issue in this paper is how the mixture of vertical and horizontal leadership affects the horizontal leader's optimal tax structure and provision of public goods. The decision-problem facing the leader is formulated as an extension of the two-type model originally developed by Stern (1982) and Stiglitz (1982). Suppose that ability-type 1 is the low-ability type and ability-type 2 the high-ability type, and that the redistribution policy carried out by the national government means redistribution from the low-ability to the high-ability type. The direct decision-problem facing the horizontal leader will then be to choose $h_{l}^{1}, c_{l}^{1}$, $h_{l}^{2}, c_{l}^{2}$ and $g_{l}$ to maximize $U_{l}=\alpha_{l}^{1} u\left(c_{l}^{1}, z_{l}^{1}, g_{l}\right)+\alpha_{l}^{2} u\left(c_{l}^{2}, z_{l}^{2}, g_{l}\right)$ subject to the budget constraint in equation (4c), the reaction functions for the federal transfer and policy variables of the follower given by equations (6), (7a) and (7b), respectively, and the following self-selection constraint:

$$
u_{l}^{2}=\left(c_{l}^{2}, z_{l}^{2}, g_{l}\right) \geq u\left(c_{l}^{1}, H-\phi_{l} h_{l}^{1}, g_{l}\right)=\hat{u}_{j}^{2} .
$$

In equation (8), $H$ is a time-endowment and $\phi_{l}=w_{l}^{1} / w_{l}^{2}<1$ is the wage-ratio, while $\hat{u}_{j}^{2}$ denotes the utility of the mimicker. For further use, we derive the total derivatives of the reaction function in equation (6) with respect to $h_{l}^{i}$ and $c_{l}^{i}$, where the indirect effects through the reaction functions $h_{f}(\cdot)$ and $c_{f}(\cdot)$ are also incorporated

$$
\begin{aligned}
\frac{d s_{l}}{d h_{l}^{i}} & =\frac{\partial s_{l}}{\partial h_{l}^{i}}+\frac{\partial s_{l}}{\partial h_{f}} \frac{\partial h_{f}}{\partial h_{i}^{i}}+\frac{\partial s_{l}}{\partial c_{f}} \frac{\partial c_{f}}{\partial h_{l}^{i}} \\
\frac{d s_{l}}{d c_{l}^{i}} & =\frac{\partial s_{l}}{\partial c_{l}^{i}}+\frac{\partial s_{l}}{\partial h_{f}} \frac{\partial h_{f}}{\partial c_{i}^{i}}+\frac{\partial s_{l}}{\partial c_{f}} \frac{\partial c_{f}}{\partial c_{l}^{i}}
\end{aligned}
$$

for $i=1,2$.

Let $M R S_{z, c}^{l, i}=\left[\partial u_{l}^{i} / \partial z_{l}^{i}\right] /\left[\partial u_{l}^{i} / \partial c_{l}^{i}\right]$ denote the marginal rate of substitution between leisure and private consumption and $M R S_{g, c}^{l, i}=\left[\partial u_{l}^{i} / \partial g_{l}\right] /\left[\partial u_{l}^{i} / \partial c_{l}^{i}\right]$ the marginal rate of substitution between the public good and private consumption for ability-type $i$, while $M \hat{R} S_{z, c}^{l, 2}$ and $M \hat{R} S_{g, c}^{l, 2}$ denote the corresponding marginal rates of substitution for the mimicker. Then, by using the short notation $\delta_{l}^{1}=1-d s_{l} / d c_{l}^{1}$, we can characterize the tax and expenditure policies of the horizontal leader as follows:

Proposition 1 In a subgame perfect equilibrium, the marginal income tax rates and policy rule for the public good implemented by the horizontal leader can be written as

$$
\begin{aligned}
& T_{l}^{\prime}\left(w_{l}^{1} h_{l}^{1}\right)=\frac{1}{\delta_{l}^{1}}\left\{\frac{\lambda_{l}^{*}}{w_{l}^{1}}\left[M R S_{z, c}^{l, 1}-\phi_{j} M \hat{R} S_{z, c}^{l, 2}\right]\right\} \\
& T_{l}^{\prime}\left(w_{j}^{2} h_{j}^{2}\right)=0 \\
& \sum_{i} M R S_{g, c}^{l, i}+\lambda_{l}^{*}\left[M R S_{g, c}^{l, 1}-M \hat{R} S_{g, c}^{l, 2}\right]=1+\sum_{i} M R S_{g, c}^{l, i} \frac{d s_{l}}{d c_{l}^{i}} .
\end{aligned}
$$


In equations (10), $\lambda_{l}^{*}=\lambda_{l}\left(\partial \hat{u}_{l}^{2} / \partial c_{l}^{1}\right) / \gamma_{l}$, where $\gamma_{l}>0$ and $\lambda_{l}>0$ denote the Lagrange multiplier associated with the government budget constraint and self-selection constraint, respectively.

We start by interpreting Proposition 1 under the assumption that incentive effect (i) for the horizontal leader (in terms of how the horizontal follower reacts) dominates incentive effect (ii) referred to above. This means that the reaction functions for $h_{f}$ and $c_{f}$ facing the horizontal leader have the comparative statics properties presented in equation (7a) and (7b), respectively. As such, equations (9a) and (9b) imply $d s_{l} / d h_{l}^{i}<0$ and $d s_{l} / d c_{l}^{i}>0$ for $i=1,2$. Proposition 1 then implies that the incentives to modify the marginal income tax rates and public provision due to decentralized leadership derived by Aronsson (2010) are reinforced by horizontal leadership. In equation (10c), $d s_{l} / d c_{l}^{i}>0$ (for $i=1,2$ ) due to the direct effect of decentralized leadership (the first term on the right hand side of equation (9b), i.e. $\partial s_{l} / \partial c_{l}^{i}>0$ ) and because of the effects created by horizontal leadership (meaning that the second and third terms on the right hand side of equation (9b) are also positive). As such, the horizontal leader has an incentive to reduce its own public revenue and underprovide the public good relative to the second best policy rule derived by Boadway and Keen (1993) both because such a policy increases $s_{l}$ through the decentralized leadership channel, and because the corresponding reduction in $s_{f}$ leads the horizontal follower to increase its own tax revenue which, in turn, induces the federal government to further increase the transfer payment to the horizontal leader.

The expression for the marginal income tax rate faced by the low-ability type does not take the same form as in the conventional two-type model. This is seen by the appearance of the scale term $1 / \delta_{l}^{1}>1$ in the formula for the low-ability type. ${ }^{3}$ The intuition is that the national government has an incentive to increase the private consumption to gain from federal redistribution, and the assumed redistribution profile means an incentive to increase the private consumption of the low-ability type. To accomplish this additional redistribution, the government must relax the self-selection constraint, which it does by increasing the marginal income tax rate of the low-ability type. Since $d s_{l} / d c_{l}^{1}>\partial s_{l} / \partial c_{l}^{1}$, we have $1 / \delta_{l}^{1}=$ $1 /\left(1-d s_{l} / d c_{l}^{1}\right)>1 /\left(1-\partial s_{l} / \partial c_{l}^{1}\right)$, implying that this effect is stronger under a mixture of decentralized and horizontal leadership than under decentralized leadership alone.

If, on the other hand, incentive effect (i) for the horizontal leader does not dominate incentive effect (ii), the comparative statics properties of equations (7) no longer necessarily apply. This situation may arise if the third order derivative of the function $v(\cdot)$ is sufficiently large in absolute value, implying that the comparative statics properties of the reaction functions for $h_{f}$ and $c_{f}$ facing the horizontal leader are ambiguous. In this case, therefore, it is possible that a decrease in $h_{l}^{i}$ and/or increase $c_{l}^{i}$ for $i=1,2$ (which leads to an increase in the transfer payment to the horizontal leader) induces the follower to reduce its own tax revenue to counteract its own corresponding loss of transfer income. As such, this tends to offset the incentive faced by the horizontal leader to act strategically by lowering its own tax revenue. Therefore, in

\footnotetext{
${ }^{3}$ Strictly speaking, this interpretation presupposes that $1-d s_{l} / d c_{l}^{1}>0$. This works as a stability condition and means that the self-selection constraint affects $T_{l}^{\prime}\left(w_{l}^{1} h_{l}^{1}\right)$ in the same qualitative way as in the original two-type model without federal redistribution.
} 
this (let be somewhat unlikely) situation, horizontal leadership may actually counteract the inefficiencies created by decentralized fiscal federalism.

\section{References}

[1] Aronsson, T. (2010) Optimal Income Taxation and Decentralized Fiscal Federalism. Regional Science and Urban Economics 40, 187-195.

[2] Aronsson, T., Jonsson, T. and Sjögren, T. (2006b) Environmental Policy and Optimal Taxation in a Decentralized Economic Federation. FinanzArchiv 62, 437-454, 2006.

[3] Boadway, R., and M.J. Keen (1993) Public Goods, Self-Selection and Optimal Income Taxation. International Economic Review 34, 463-478.

[4] Caplan, A., Cornes, R. and Silva, E. (2000) Pure Public Goods and Income Redistribution in a Federation with Decentralized Leadership and Imperfect Labor Mobility. Journal of Public Economics 77, $265-284$.

[5] Caplan, A. and Silva, E. (1999) Federal Acid Rain Games. Journal of Urban Economics 46, 25-52.

[6] Köthenbürger, M. (2004) Tax Competition in a Fiscal Union with Decentralized Leadership. Journal of Urban Economics 55, 498-513.

[7] Köthenbürger, M. (2007) Ex-Post Redistribution in a Federation: Implications for Corrective Policy. Journal of Public Economics 91, 481-496.

[8] Silva, E. and Caplan, A. (1997) Transboundary Pollution Control in Federal Systems. Journal of Environmental Economics and Management 34, 173-186.

[9] Stern, N.H. (1982) Optimum Taxation with Errors in Administration. Journal of Public Economics 17, $181-211$.

[10] Stiglitz, J.E. (1982) Self-Selection and Pareto Efficient Taxation. Journal of Public Economics 17, 213240. 